\title{
Farklı Malzemeler ve Geosentetiklerin Yol Dolgusu Güvenliğine ve Davranışına Etkileri
}

\section{Elif Çiçek ${ }^{1, *}(\mathbb{1})$}

${ }^{1}$ Hacettepe Üniversitesi, Mühendislik Fakültesi, Inşaat Mühendisliği Bölümü, 06800, Ankara.

\section{Özet}

Bu çalışmada, doğal ve atık malzemelerin geri kazanımından elde edilen yeni malzemeler ile oluşturulmuş yol dolgusu modelleri sonlu elemanlar yöntemi kullanılarak analiz edilmiştir. Kumlu silt, kaya agregası, beton, cam gibi farklı malzemelerin yol dolgusuna etkileri incelenmiş ve atık liflerin yol dolgusunda kullanıldığı modellerin analiz sonuçları doğal koşullar ile karşılaştırılmıştır. Ayrıca farklı geosentetik donatı sayılar ile güçlendirilmeye çalışılan yol dolgusu modelleri için de hesaplamalar yapılmıştır. Böylece oluşturulan yol modelinin güvenlik sayısına farklı malzemelerin, liflerin ve geosentetik sayısının etkileri incelenmiştir. Yolun ani gö̧̧mesine karşı değerlendirmeler yapılarak, dolgu altındaki yeraltı suyundan kaynaklanacak konsolidasyon davranışının da etkileri farklı malzeme koșulları için karșılaștırılmıștır. Ayrıca, farklı malzemeler kullanılarak inşa edilen dolgularda yolun farklı bölgelerinde trafik yükünden oluşabilecek oturma farkları da değerlendirilmiş ve geosentetiğin etkileri de belirlenmeye çalışılmıştır. Sonuçlar incelendiğinde hem çevreci hem de daha verimli çözümler için değerlendirmeler yapılmıştır. Atık malzemelerin geri dönüşümü ile elde edilen malzemelerin, yol dolgularının stabilite ve güvenlikleri için önemli katkılar sağlayabileceği gözlenmiştir.

\section{Anahtar Sözcükler}

Atık Malzeme, Geosentetik, Yeraltı Suyu, Oturma, Yol Dolgusu, Güvenlik

\section{The Effects of Different Materials and Geosynthetics on Embankment Safety and Behavior}

\begin{abstract}
In this study, road embankment models constructed with new materials obtained from the recycling of natural and waste materials were analysed using the finite element method. The effects of different materials such as sandy silt, rock aggregate, concrete, glass on the road fill were investigated and the results of the analysis of the models using waste fibers in the road fill were compared with the natural conditions. In addition, calculations have been made for road embankment models which are tried to be reinforced with different numbers of geosynthetic reinforcement. Thus, the effects of different materials, fibers and geosynthetics on the number of safety of the road model created were examined. Evaluations were made against the collapse of the road and the effects of the consolidation behaviour arising from groundwater under filling were compared for different material conditions. In addition, the residence differences that may be caused by traffic load in different parts of the road in the fillings constructed using different materials were evaluated and the effects of geosynthetics were tried to be determined. When the results were examined, evaluations were made for both environmental and more efficient solutions. It has been observed that the materials obtained by recycling of waste materials can make significant contributions to the stability and safety of road embankments.
\end{abstract}

$\underline{\text { Keywords }}$

Waste Material, Geosynthetic, Groundwater, Settlement, Road Embankment, Safety

\section{Giriş}

Bilindiği üzere, nüfus arttıkça her geçen gün doğal kaynaklar tüketilmekte ve daha fazla atık üretilmektedir. Atık malzemelerin doğru yönetilmesi ile afetlerin önüne geçilebileceği ve yararlı sonuçlar alınabileceği düşünülmektedir. Böylece, geri kazanım ile malzemelerin yeniden farklı alanlarda kullanılması hem çevre hem de ekonomik yararı bakımından büyük önem taşımaktadır. Bu nedenle, son yıllarda bu konu ile ilgili çeşitli alanlarda yapılan çalışmalar hız kazanmıştır (Oikonomou 2005; Evangelista ve Brito 2007). Kilometrelerce alanda etkin rol oynayan yolların oluşturulmasında ise malzeme sıkıntısı yaşanmaktadır. Böylece, kullanılan granül malzemeler yerine veya güçlendirmek için atık malzemelerin geri dönüşümlü formlarının ulaştırma yapılarında kullanımı ile ilgili çalışmalar ilgi görmektedir (Arulrajah vd. 2013; Rahman vd. 2013). Fakat bu malzemelerin karayolunda kullanımında güvenlik ve trafik yükündeki davranışı hakkında henüz tam kesinleşmiş bir bilgi bulunmadığından ötürü konunun incelenmesinin önemi aşikârdır. 
Literatür incelendiğinde, bazı ülkelerde 1970'lerin sonlarından bu yana geri kazanım teknikleri uygulandığı belirlenmiştir. Örneğin, Molenaar ve van Nierkerk (2002), geri dönüşümlü beton ve duvar molozlarından geri kazanılan malzemelerinin performanslarını incelemişlerdir. Poon ve Chan (2006), Hong Kong'daki geri kazanılmış beton agregası ve kil tuğlasının özelliklerini incelemişledir. Araştırma sonuçlarında, \% 100 geri dönüştürülmüş beton agregasının kullanımının, optimum nem içeriğini arttırdığı ve doğal malzemelerden oluşan agrega kullanımına kıyasla maksimum kuru yoğunluğu azalttığını gösterilmiştir. Herrador vd. (2012) inşaat atıklarının yol kaplamalarında kullanılmasının teknik uygulanabilirliği üzerine bir çalışma yapmışlardır. Bu amaçla, beton, asfalt karışımı ve seramik atık agregadan oluşan kaplamaların performansı saha çalışması ile incelenmiştir. Araç trafiği etkisindeki bir yolda geri dönüştürülmüş malzemenin özellikleri analiz edilmiş ve geri kazanılmış yapay agreganın taşıma kapasitesinin yeterli olduğu görülmüştür. Böylece farklı malzemelerin aynı yol yapısındaki etkilerinin incelenmesinin önemli olduğu belirlenmiştir. $\mathrm{Bu}$ çalışmada, literatürden mekanik özellikleri alınan farklı malzeme tiplerinin ve geri dönüşmüş atıkların yol dolgusunda nasıl bir etki bırakacağı ile ilgili sonlu elemanlar analizleri yapılmıştır.

Bilindiği üzere atık maddelerden elde edilen lifler, geosentetikler, cam ve beton atık parçalarının farklı inşaat yapılarında kullanımı ile normal doğal agregaların yol dolgularındaki etkilerinin belirlenmesi önemlidir. Bu nedenle, lifli ve geosentetikli yol dolgusunun etkileri bu çalışmada incelenmiştir. Ayrıca, bir yolun güvenlik sayısı ve oturma davranışı büyük önem taşımaktadır. Özellikle yumuşak zeminler üzerindeki yol dolgularının stabilitesi hassastır. İyileştirme yöntemlerine göre nispeten daha hızlı olan geosentetik kullanımı, göçmeye karşı güvenlik sayısında önemli mertebede artış gösterebilmekte ve şev eğimini daha dik hale getirilebilmektedir. Fakat geosentetikler sistemin taşıma güvenliğini artırsa da uzun dönem konsolidasyon oturmasını önleyememektedir (Çicek vd. 2015). Yeraltı suları tüm inşaat yapılarının zarar görmesi ve göçmesinde etkin rol oynayabilen doğal bir etkendir. Özellikle yol dolgularının son yıllarda göçmesinin artması bu konunun önemini göstermektedir. Bilindiği üzere trafik akışının rahat sağlanması için yol dolgularının davranışının bilinmesi önemlidir. Yol göçüklerinden ötürü meydana gelen hasar ve trafik akışının engellenmesi çevre şartlarını da kötü etkilemektedir. Böylece, farklı tip malzemelerin etkilerinin değişik konsolidasyon koşullarında değerlendirilmesi değerlidir. Geosentetikli yol dolguları ile ilgili son yıllarda yapılan çalışmalara bakıldığında genellikle stabiliteye etkilerinin veya konsolidasyona etkilerinin incelendiği gözlemlenmiştir. Örneğin, Çicek vd. (2015) sonlu eleman analizlerinde donatısız olarak inşa edildiği takdirde göçen bir dolgu şevin geosentetik donatı sayısı artırılarak ve farklı donatı uzunluklu kullanılarak stabiliteye ve şev eğimine etkilerini incelemişlerdir. Sonuç olarak, geosentetik donatıların şev göçmesini engelleyerek stabiliteyi önemli ölçüde arttırdığı, zemin taneciklerinin derinlere doğru hareket etmesini sağlayarak daha büyük kayma yüzeyi ve taşıma kapasitesi oluşturduğunu belirtmişlerdir. Donatı boyunun da önem taşıdığı ve şev eğimin de etkili olduğu görülmüştür. Yu vd. (2017) sonlu eleman analizlerinde yumuşak zemindeki bir ve iki donatı sayılı dolgularda iki donatının şev stabilitesi için daha iyi performans verdiğini söylemişlerdir.

Bir yolun taşıt trafiğine açlabilmesi için hem güvenlik sayısının hem de trafik yükünden oluşabilecek oturma miktarının güvenli tarafta kalması gerekmektedir. Dahası, konsolidasyon sonrasındaki ani oturmalarla da göçmeler oluşmamasına ve ani oturmalara dikkat edilmelidir. Yol dolgusunu oluşturabilecek çevreci çözümlerin bu standartları da yerine getirebilmelerinin incelenmesi önemlidir. Böylece, son yıllarda meydana gelen ani yol göçmelerinin önüne nasıl geçilebileceği ile ilgili de ön bir çalışma yapılmış olacak ve gelecekte yapılabilecek yeni çalışmalara 1şı tutması sağlanacaktır. Bilindiği üzere literatürde birçok araştırma tekniği vardır ve sonlu eleman metodu ile analizler yapılması da bunlardan yaygın ve kabul görmüş olanlarındandır. Özellikle yolların davranışının incelenmesi için gerçeğe yakın sonuçların elde edilmesi hususunda araştırmacılara önemli bilgiler sunmaktadır. Son yıllarda ise bir çok ulaştırma problemi bu teknik ile incelenmektedir (Saevarsdottir ve Erlingsson 2015; Ramos-García ve Castro 2017; Djellali vd. 2017; Ahirwara ve Mandala 2017; Zhang vd. 2017). Bu çalışmada da dünyaca kabul edilmiş olan bu teknik kullanılarak araştırma yapılmıştır.

Yapılan bu araştırma kapsamında literatürden seçilen doğal ve atık malzemelerin geri dönüşümünden elde edilen agregalar ile oluşturulmuş yol dolgusu modelleri analiz edilmiştir. İlk olarak, kumlu silt ile oluşturulan yol dolgusu ile atık liflerin bu dolgu içine konularak güçlendirilmesi ile oluşturulan modellerin konsolidasyonu, güvenlik sayısı ve oturma davranışları incelenmiştir. Ayrıca, betonun geri dönüşümünden elde edilen agrega ile oluşturulan yol dolgusu ve cam agreganın kaya ile beton agregalar ile ayrı ayrı karıştırılması ile elde edilen modeller ile karşılaştırılmıştır. Böylece atık malzemelerin sonlu eleman analizleri değerlendirilmiştir. İlaveten, geosentetik donatının kumlu silt ve lifli kumlu silt malzemelerle oluşturulan yol dolgu modelleri arasındaki farklar incelenmiştir. Böylece farklı geosentetik donatı sayılarının değişik malzemeler üzerindeki etkileri belirlenmeye çalışılmıştır. Sonuçlar değerlendirilerek hem çevreci hem de daha verimli çözümler için değerlendirmeler yapılmıştır.

\section{Materyal ve Yöntem}

Bu çalışmada, sonlu eleman yöntemi kullanılarak analizler yapılmıştır. İşlemlerin daha kolay ve hızlı yapılabilmesi amacıyla hazır bir bilgisayar programı olan Plaxis programı kullanılmıştır. İki boyutlu olarak yapılan analizlerde yol dolgusu ve diğer zemin modelleri literatürden seçilmiştir (Jamsawang vd. 2016; Park ve Tan 2005; Ali 2012; Brinkgreve vd. 2018). Araştırmada kullanılan yol dolgu modeli Şekil 1'de verilmektedir. Sistem simetrik olduğu için yolun yarısı modellenerek analizler yapılmıştır. 
Modelin düşey sınırlarında yatay yöndeki, taban sınırında ise hem yatay hem de düşey yöndeki hareket engellenmiştir. En altta ve üstte kum ortada ise kil olan bir arazi koşulunda yol dolgusu yapılma durumu dikkate alınmıştır. Kum zemin yüzeyinden $1.5 \mathrm{~m}$ aşağıda ise yeraltı su seviyesi (YASS) başlamaktadır. Yol dolgusu $16 \mathrm{~m}$ genişliğinde ve $4 \mathrm{~m}$ yüksekliğinde olup şev eğim uzunluğu $12 \mathrm{~m}$ olarak alınmıştır. Yol dolgusunun altındaki arazide ise su drenajının sağlanması için $2 \mathrm{~m}$ aralıklarla drenler oluşturulmuştur (Şekil 1). Yol dolgusunda kullanılan farklı malzeme türleri Tablo 1'deki gibidir. Yol modelindeki kum ve yumuşak kil zemin özellikleri ise Tablo 1 ve Tablo 2'de verilmektedir. Kum ve dolgu malzemeleri genellikle Mohr-Coulomb modeli, kil ise Yumuşak zemin modeli ile programa tanımlanmıştır. Mesh modeli olarak sık mesh aralığı alınmış ve donatılar arası yeniden sıklaştırılmıştır.

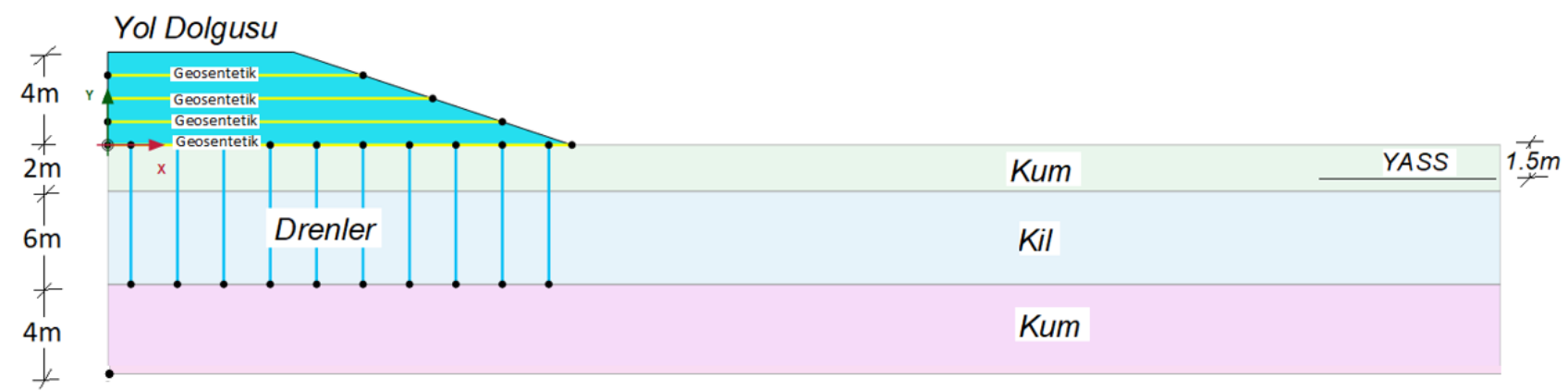

Şekil 1: Yol dolgu modeli

Tablo 1: Zemindeki kum malzemesi özellikleri

\begin{tabular}{|c|c|c|c|}
\hline Parametre & Simge & Birim & Değer \\
\hline Kuru birim hacim ağırlık & $\gamma \mathrm{k}$ & $\mathrm{kN} / \mathrm{m}^{3}$ & 20 \\
\hline Doygun birim hacim ağırlık & $\gamma \mathrm{d}$ & $\mathrm{kN} / \mathrm{m}^{3}$ & 22 \\
\hline Permeabilite katsayısı & $\mathrm{k}$ & $\mathrm{m} / \mathrm{gün}$ & 7,12 \\
\hline Young modülü & $\mathrm{E}$ & $\mathrm{kN} / \mathrm{m}^{2}$ & 30000 \\
\hline Kohezyon & $\mathrm{c}$ & $\mathrm{kN} / \mathrm{m}^{2}$ & 0 \\
\hline Kayma mukavemet açısı & $\varphi$ & $\left(^{\circ}\right)$ & 33 \\
\hline Poisson oranı & $\mathrm{v}$ & - & 0,33 \\
\hline
\end{tabular}

Tablo 2: Kil zeminin özellikleri

\begin{tabular}{|c|c|c|c|}
\hline Parametre & Simge & Birim & Dĕger \\
\hline Kuru birim hacim ağırlık & $\gamma \mathrm{k}$ & $\mathrm{kN} / \mathrm{m}^{3}$ & 15 \\
\hline Doygun birim hacim ağırlık & $\gamma \mathrm{d}$ & $\mathrm{kN} / \mathrm{m}^{3}$ & 18 \\
\hline Permeabilite katsayısı & $\mathrm{k}$ & $\mathrm{m} / \mathrm{gün}$ & 0,047 \\
\hline Şişme indeksi & $\mathrm{k}^{*}$ & - & 0,05 \\
\hline Modifiye sıkışma indeksi & $\lambda^{*}$ & - & 0,05 \\
\hline Kohezyon & $\mathrm{c}$ & $\mathrm{kN} / \mathrm{m} 2$ & 1 \\
\hline Kayma Mukavemet Açıs1 & $\varphi$ & $\left(^{\circ}\right)$ & 25 \\
\hline Permeabilitedeki değişim & $\mathrm{c}_{\mathrm{k}}$ & - & 0,2 \\
\hline
\end{tabular}

Yol dolgusu olarak öncelikle kumlu silt ile işlemler yapılmıştır. Bilindiği üzere atık malzemelerden üretilen lifler zemin içinde kullanılarak daha güçlü zeminler elde edilebilmektedir. Böylece lifle karıştırılmış kumlu silt için de analizler yapılmıştır. Bu malzemelerin özellikleri daha öncede bahsedildiği gibi literatürden alınmıştır. Kumlu siltin gradasyon gibi malzeme özellikleri Park ve Tan (2005)'ın yaptıkları çalışmada belirtilmektedir. Kullanılan lifin özgül yoğunluğu 0.91, çekme gerilmesi 350-770 MPa ve Young modülü 3500 MPa'dır (Park ve Tan 2005). Kayadan elde edilen agrega, betonun kırılarak geri dönüşümle yol dolgusunda kullanılabilecek agrega malzemesi için de analizler tekrar edilmiştir. Cam agrega tek başına şevde kullanılamadığından ötürü \%15 oranında kaya agrega veya geri dönüşümden elde edilen beton atığının agrega olarak kullanılması durumundaki malzeme ile karıştırılmıştır. Yol dolgu malzeme özellikleri Tablo 3 'te verilmiştir. 
Tablo 3: Yol dolgusu özellikleri

\begin{tabular}{|c|c|c|c|c|c|c|c|c|}
\hline Parametre & Simge & Birim & $\begin{array}{c}\text { Kumlu } \\
\text { Silt }\end{array}$ & $\begin{array}{c}\text { Lifli } \\
\text { Kumlu } \\
\text { Silt }\end{array}$ & $\begin{array}{c}\text { Kaya } \\
\text { agrega } \\
(\text { CR10 } \\
\text { 0) }\end{array}$ & \begin{tabular}{|c|} 
Geri \\
dönüştürülm \\
üş beton \\
agrega \\
(RCC100)
\end{tabular} & $\begin{array}{c}\text { Cam } \\
\text { 15/Kaya } \\
\text { agrega85 } \\
(\text { Rg15/cr8 } \\
5)\end{array}$ & \begin{tabular}{|c|} 
Cam \\
15/Beton \\
agrega85 \\
$($ Rg15/Rcc8 \\
$5)$
\end{tabular} \\
\hline $\begin{array}{l}\text { Kuru birim } \\
\text { hacim ağırlık }\end{array}$ & $\gamma \mathrm{k}$ & $\mathrm{kN} / \mathrm{m}^{3}$ & 16 & 16 & 22.56 & 19.33 & 21.97 & 19.33 \\
\hline $\begin{array}{l}\text { Doygun birim } \\
\text { hacim ağırlık }\end{array}$ & $\gamma \mathrm{d}$ & $\mathrm{kN} / \mathrm{m}^{3}$ & 19 & 19 & 24.52 & 22 & 23.85 & 21.69 \\
\hline $\begin{array}{l}\text { Permeabilite } \\
\text { katsayis1 }\end{array}$ & $\mathrm{k}$ & $\mathrm{m} /$ gün & 3.5 & 3.5 & 3.5 & 3.5 & 3.5 & 3.5 \\
\hline $\begin{array}{l}\text { Young } \\
\text { modülü }\end{array}$ & $\mathrm{E}$ & $\mathrm{kN} / \mathrm{m}^{2}$ & 38000 & 46000 & 57000 & 59000 & 57000 & 56000 \\
\hline Kohezyon & $\mathrm{c}$ & $\mathrm{kN} / \mathrm{m}^{2}$ & 27 & 30 & 69.60 & 75.40 & 59.30 & 51.20 \\
\hline $\begin{array}{c}\text { Kayma } \\
\text { mukavemet } \\
\text { açısı }\end{array}$ & $\varphi$ & $\left({ }^{\circ}\right)$ & 21 & 21 & 48.3 & 51 & 47.20 & 48.10 \\
\hline Poisson oran1 & $\mathrm{v}$ & - & 0.40 & 0.40 & 0.35 & 0.35 & 0.35 & 0.35 \\
\hline
\end{tabular}

Öncelikle, Tablo 3'de verilen farklı malzemeler yol dolgusu olarak kullanılarak analizler yapılmıştır. Daha sonra ise yol dolgusunu güçlendirmek için Geosentetik donatı kullanılmıştır ve programa $3200 \mathrm{kN} / \mathrm{m}$ eksenel rijitlik parametresine sahip izotropik olarak tanımlanmıştır (Liu ve Won 2009). Geosentetik donatılı analizler kumlu silt ve lifli kumlu silt dolgular için yapılmış ve geosentetiğin güvenlik sayısı ve analiz sonuçlarına etkisi incelenmiştir.

Analizlere başlamadan önce arazi koşullarında en üstte kum olacak şekilde bir model tasarlanmıştır. Daha sonra yol dolgusunun ilk iki tabakası yani 2 m yükseklikteki kısmı 2 günlük bir süre ile serildiği düşünülmüş ve bu şekilde de konsolidasyona maruz kalabileceği analizlerde programa tanımlanmıştır. $2 \mathrm{~m}$ yükseklikli yol dolgusu serildikten sonra 30 günlük konsolidasyon beklemesi yapılmıştır. Sonrasında ise 1 gün süre ile son $2 \mathrm{~m}$ yükseklikli bölümün serildiği düşünülerek konsolidasyonda maksimum boşluk suyu basıncının $1 \mathrm{kN} / \mathrm{m}^{2}$ olacağı şekilde analiz basamağ1 oluşturulmuştur (Brinkgreve vd. 2018). Üst dolgu serildikten hemen sonra ve minimum boşluk suyu basıncı analizinden sonra olmak üzere iki farklı güvenlik analizi yapılmıştır. Geosentetik donatılı analizlerde ise, ilk olarak dolguda donatı olmaması durumu (Model A) göze alınmıştır. Daha sonra ise geosentetik donatının dolgunun hemen altında olma durumu (Model B), dolgu altı ve dolgu ortasında olması (Model C) ile toplamda 2 adet kullanılması ve 4 adet kullanılması (Model D) durumları için tüm analizler yenilenmiştir (Şekil 2).

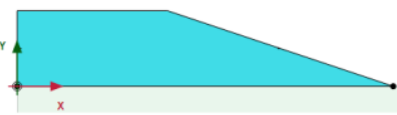

a

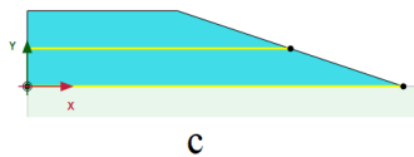

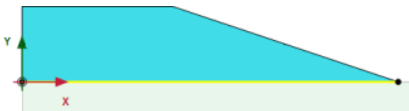

b

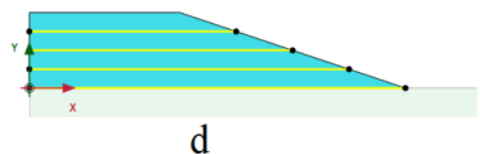

Şekil 2: Analiz modelleri; a) donatısız model, b) tek donatılı model, c) iki donatılı model, d) dört donatılı model

Güvenlik sayılarının bulunması için Phi-c azaltma yöntemi kullanılmıştır. Bu yöntemde, zemin parametreleri olan kayma mukavemeti açısı $(\varphi)$ ve kohezyon (c) kademeli olarak azaltılarak modelin göçtüğü an belirlenmekte ve şevin göçmeye karşı güvenlik sayısı hesaplanabilmektedir. Analizin herhangi bir safhasında güvenlik sayısı (G):

$G=\frac{\tan \varphi i}{\tan \varphi r}=\frac{c i}{c r}$

olarak hesaplanmaktadır. Buradaki "i" indisi malzeme özellikleri tanımlanırken ilk değerleri, "r" indisi ise analizlerde kullanılan azaltılmış değerleri belirtmektedir. Analizlerde $\varphi$ ve c parametreleri kademeli olarak azaltılarak her seferinde yeniden analiz yapılmakta ve böylece yapının göçmesi sağlanmaktadır (Brinkgreve vd. 1998; Çiçek vd. 2015). 
Ayrıca, araştırmada $15 \mathrm{~cm}$ genişlikli bir trafik yükünün dolgunun sol kenar (yani yolun ortası) ve uç kısmında (yani yol şevine yakın bölgede) nasıl bir etki yaratacağı ile ilgili de ek analizler yapılmıştır. Tek araç geçişinde gözlemlenebilecek Şekil 3'teki gibi ivme-zaman grafiğine sahip yükün sabit genişlikte dinamik olarak uygulandıktan sonra oluşan teker izleri de incelenmiştir.

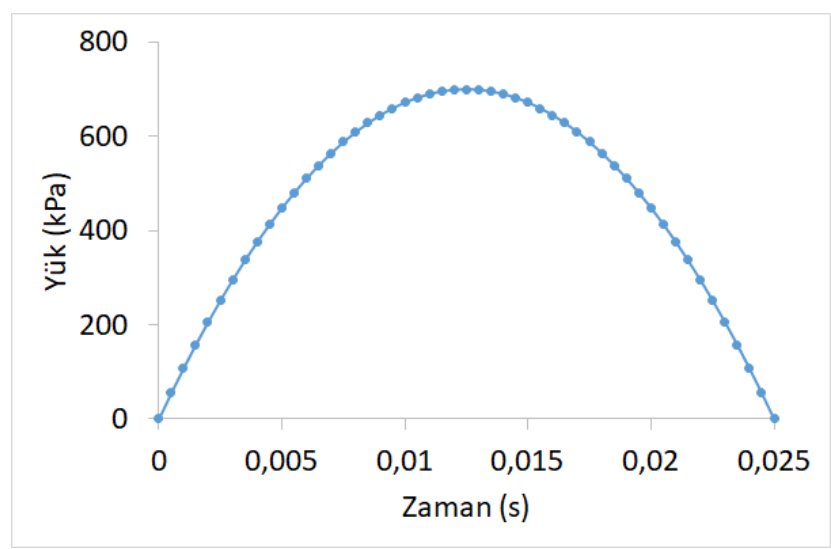

Şekil 3: Yükleme-zaman grafiği

\section{Bulgular ve Tartışma}

Öncelikle, farklı malzeme türlerinin yol dolgusuna etkileri güvenlik analizleri ile incelenmiştir. Yol dolgusu inşa edildikten sonra konsolidasyon analizi yapılarak maksimum boşluk suyu basıncının $1 \mathrm{kN} / \mathrm{m}^{2}$ olması durumunda hesaplanan güvenlik sayıları Tablo 4'teki gibidir. Farklı malzeme türlerinin yol dolgusuna etkisi incelendiğinde her malzeme türünün kendi içinde değişik davranabildiği görülmüştür. Güvenlik sayısı tüm malzeme türünde 1'den daha büyük çıkmış ve yol dolgusu güvenli bir şekilde taşınmıştır. Kumlu silt içine atık lif konulduğunda yol dolgusunun güvenliğini arttırdığı görülmüştür. Bu durumun nedeni olarak lifli durumda Young modül ve kohezyonun etkisi ile daha iyi bir davranışın oluşabileceği düşünülmektedir. Beton atıklarının geri dönüşüm ile parçalanarak agrega gibi kullanılması durumunda ise çok daha iyi bir yol dolgusu elde edilmiştir. Ayrıca, cam atıklarından üretilen agrega beton agrega ile karıştırıldığında kaya agregadan daha güvenli bir sonuç vermiștir. Farklı malzeme özellikleri için Tablo 1, 2 ve 3 'te verilen kohezyon ve Young Modülü gibi değerlerin etkileri ile daha iyi davranışlar gözlemlenebilmiştir. Yol altında kum malzemelerin olması yapım sonrası ile konsolidasyon sonrasındaki güvenlik sayıları arasındaki farkın az olmasını sağlamıştır. Fakat Şekil 4 incelendiğinde konsolidasyon sonrasında güvenliğin daha fazla olduğu görülmüştür. Şekil 5 incelendiğinde ise farklı malzeme türlerinin yol dolgusu olarak kullanılmaları halinde yapım sonrası ile konsolidasyon sonrası elde edilen güvenlik sayıları arasındaki farkın da değiştiği belirlenmiştir. Kaya agreganın en fazla farkı verdiği ve kumlu siltli yol dolgusunun ise güvenlik sayısı açısından daha az fark oluşturduğu belirlenmiştir. Farklı atıkların geri dönüşümle yol dolgusunda kullanılmaları ise ortalama değişimler göstermişstir.

Tablo 4: Analizler sonucu elde edilen güvenlik sayıları

\begin{tabular}{|c|c|c|}
\hline \multirow{2}{*}{ Yol Dolgusu } & \multicolumn{2}{|c|}{ Güvenlik sayısı } \\
\cline { 2 - 3 } & Yapım sonrası & Minimum boşluk basıncı sonrası \\
\hline Kumlu silt & 2,971 & 2,982 \\
\hline Lifli kumlu silt & 3,011 & 3,024 \\
\hline Kaya agrega & 2,734 & 2,762 \\
\hline Beton agrega & 3,034 & 3,056 \\
\hline Cam 15/Kaya agrega85 & 2,755 & 2,781 \\
\hline Cam 15/Beton agrega85 & 2,968 & 2,988 \\
\hline
\end{tabular}




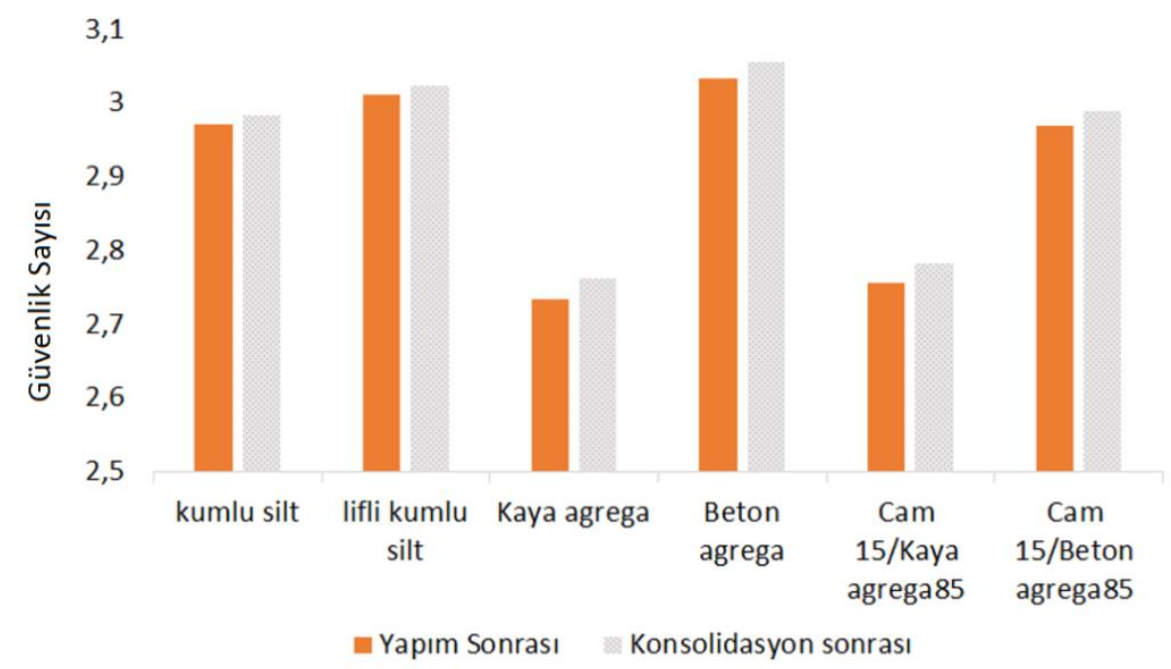

Şekil 4: Farklı malzemelerin yol dolgusu güvenlik sayısına etkisi

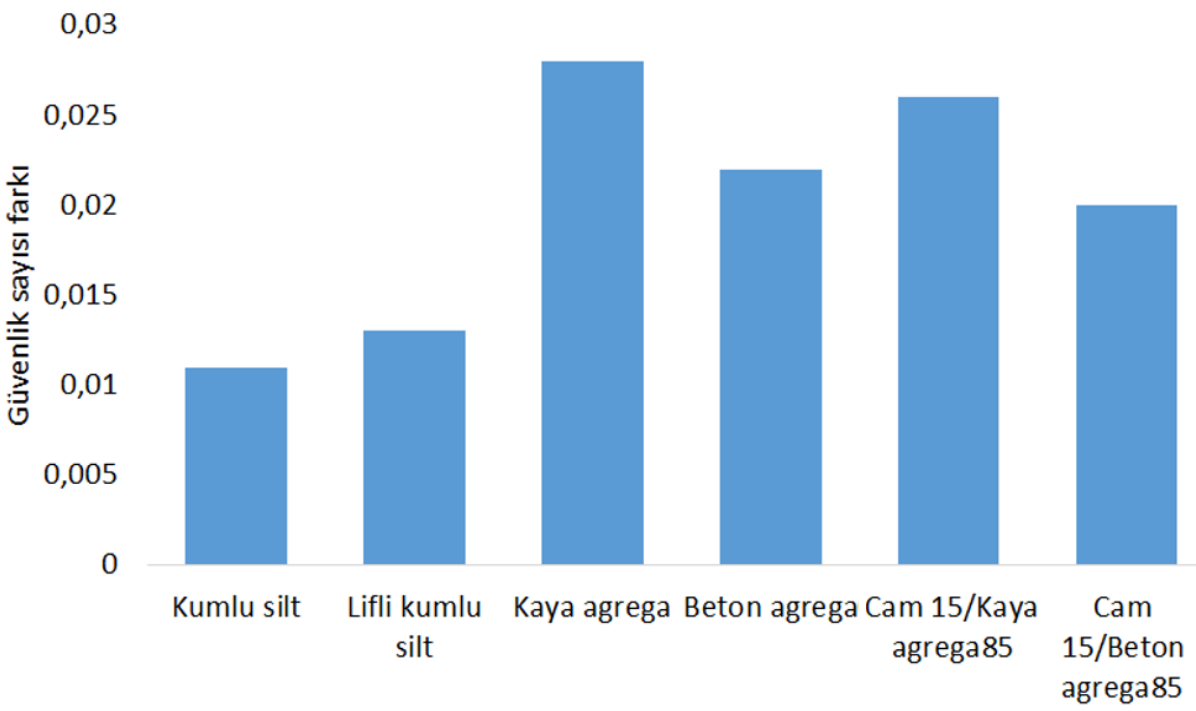

Yol dolgusu malzemesi

Şekil 5: Farklı malzemelerle inşa edilmiş yol dolgusu güvenlik sayısına konsolidasyonun etkisi

Çalışma kapsamında, geosentetiklerin yol dolgusuna etkisi de incelenmiştir. Sadece iki farklı malzeme modeli seçilerek yol dolgu modelleri arasındaki farklar değerlendirilmiştir. Bunlardan birisi, kumlu siltin atık lastik ile güçlendirilmesi ile yapılan yol dolgusunda eşit aralıklarla geosentetik konulmasının etkilerinin belirlenmesidir. Lifli ve lifsiz durumda geosentetiğin etkilerinin görülmesi açısından bu iki model tercih edilmiştir. Şekil 2'deki gibi farklı konfigürasyonlarda konulan geosentetiğin dolgu güvenliğine etkileri Şekil 6 ve Şekil 7'deki gibi incelenmiştir. Kumlu silt ile yol dolgusu yapımında dolgu içine geosentetik donatı konulduğunda tek donatı kullanılması bile güvenlik sayısını 1.5 kat arttırmıştır. Fakat donatı sayısının 2 ve 4'e çıkarılması, güvenlik sayısını çok fazla etkilememiştir. Ayrıca, lif ile birlikte kullanıldığında geosentetik donatının daha farklı davrandığı ve sentetik sayısının dolgu içinde artmasının güvenlik sayısını da değiştirdiği gözlenmiştir. Böylece farklı malzeme türlerinde geosentetiğin etkisinin de değişebildiği düşünülmektedir. Lif konulduğunda geosentetik donatının etkisi lifsiz duruma nazaran daha az olmuştur. Malzeme ne kadar zayıfsa geosentetiğin etkisi de artabilmektedir. 


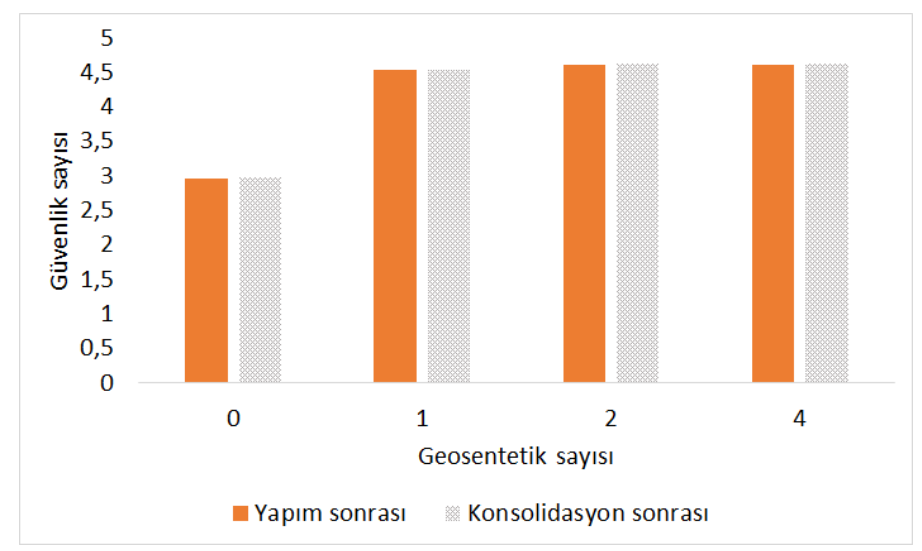

Şekil 6: Kumlu siltle inşa edilmiş yol dolgusu güvenlik sayısına geosentetiğin etkisi

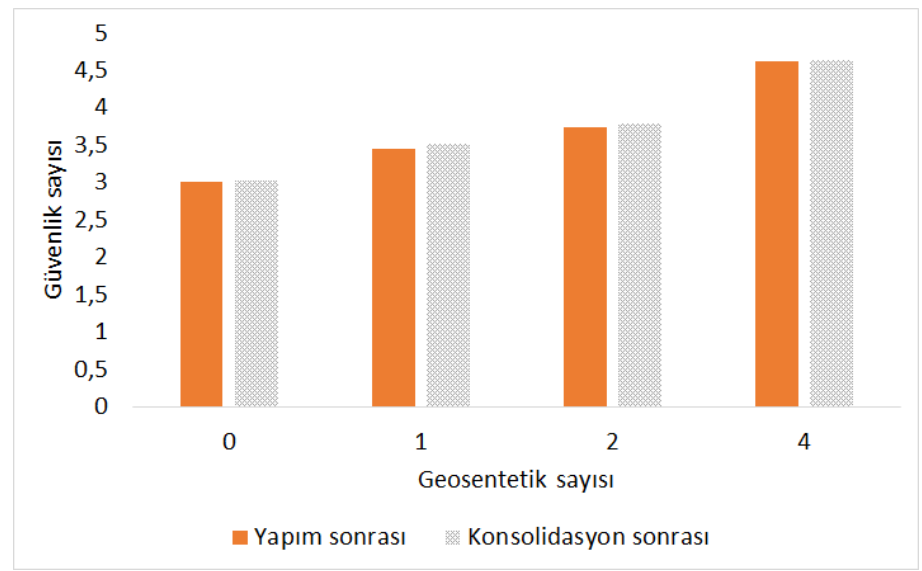

Şekil 7: Lifli kumlu siltle inşa edilmiş yol dolgusu güvenlik sayısına geosentetiğin etkisi

Geosentetiğin konsolidasyon sonrası güvenlik sayısına etkisi ise Şekil 8'deki gibi incelenmiştir. Kumlu siltte yani doğal zemin malzemesi yol dolgusu olarak kullanıldığında dolgu yapımı bittikten ve konsolidasyon tamamlandıktan sonraki güvenlik sayıları arasındaki fark, geosentetik ile artmıştır. Fakat lifli durumda geosentetiğin dolgunun içine konması daha farklı bir etki yaratmıştır. Geosentetik donatı sayısı arttıkça konsolidasyonun etkisi de azalmıştır. Böylece farklı malzemeler yol dolgusu için kullanıldığında değişik etkiler görülebileceği, sabit bir yaklaşım olamayabileceği ve dolgunun su drenajı ve güvenlik sayılarına etkilerinin de değişebileceği düşünülmüştür. Bu nedenle uygulayıcıların yol yapımında daha dikkatli olması ve ön analizlerin daha detaylı yapmaları gerekliliği belirlenmiştir. Literatürde geosentetiğin kumlu bir dolguya konulduğunda şev açısını etkileyebileceği ve daha sağlam yol yapımında etkili olabileceği bilinmektedir. Fakat bu çalışma, farklı yol dolgu malzemelerinde bu etkiler önemli değişimlerin gözlenebileceğini göstermiştir.

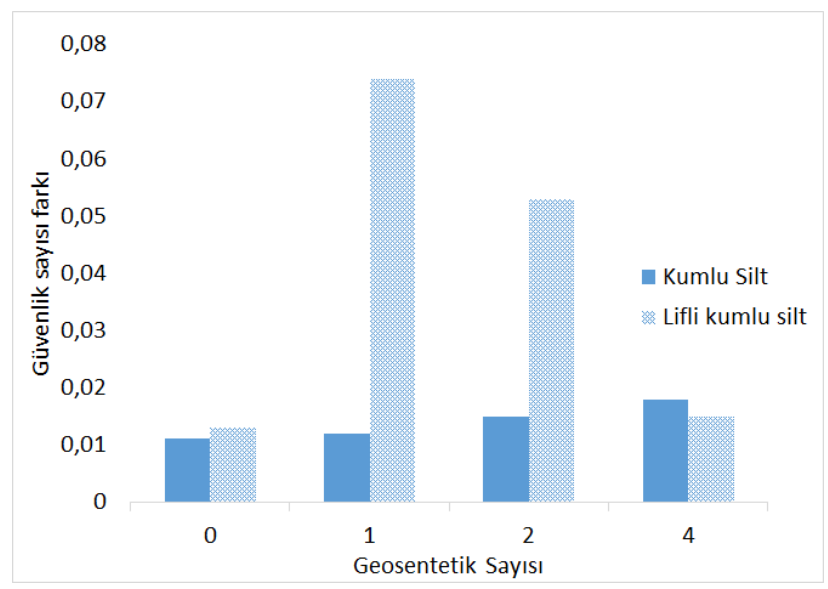

Şekil 8: Geosentetiğin konsolidasyon sonu güvenlik katsayısına etkisi 
Ayrıca, bu çalışma kapsamında, farklı yol dolgusu malzemelerinin trafik yükünden dolayı yolda oluşabilecek oturmalara etkileri de incelenmiştir. Bilindiği üzere trafik akışı yol dolgusunun merkezinde veya şev kenarına yakın bir alanda da olabilir. Böylece bu çalışmada hem en son kenarda hem de sağ kısımda yüklemelerin olabileceği şekilde iki farklı yükleme modeli ile analizler tekrarlanmıştır. $15 \mathrm{~cm}$ genişliğindeki tekerlek yükü düşünülerek dinamik yani trafik yükleme modeli ile tek bir araç geçişi sonrası görülebilecek maksimum oturmalar farklı dolgu malzemeleri için hesaplanmıştır. Şekil 9'da yükün farklı bölgelerde etki etmesi durumlarında oluşabilecek toplam oturma tipleri görülmektedir. Kumlu silt için verilen örnekte, yükleme durumunun devam etmesi ile yol şevinin negatif etkilenebileceği düşünülmektedir. Yükün etkisi ile yolun sol kısmında daha fazla oturma meydana gelebilmektedir. Sağ kısımda ise daha geniş bir alanda oturmaya neden olmaktadır. Bu oran nerdeyse iki kat kadar bir farkla oluşmaktadır. Şekil 10'da ise farklı yol dolgu malzemelerinin trafik yükünden kaynaklı oturmalara etkisi görülmektedir. Malzeme açısından incelendiğinde ise yolda meydana gelebilecek tekerlek etkisi yani oturma en az beton agrega olarak kullanıldığında en fazla ise kumlu siltte gözlenmiştir. Kumlu siltin oturması diğer malzemelere nazaran nerdeyse iki kat olmuştur. Kuma lif atık eklendiğinde oturma miktarının azaldığı belirlenmiştir. Bu durum, yoldaki deformasyonların azalması hususunda önemli bir etkidir. Bu çalışmada seçilen malzeme ve parametrelerin ötesinde gerçek deneylerin de yapılması gerektiği ve gerçek malzeme özellikleri ile yol dolgu denemeleri yapılarak değişimlerin incelenmesi gerekliliği de belirtilmektedir. Ayrıca, yapılan çalışmanın, araştırmacılara gelecekte yapabilecekleri laboratuvar veya uygulama alanı koşullarındaki testleri için önemli bir bakış açısı kazandıracağı düşünülmektedir.

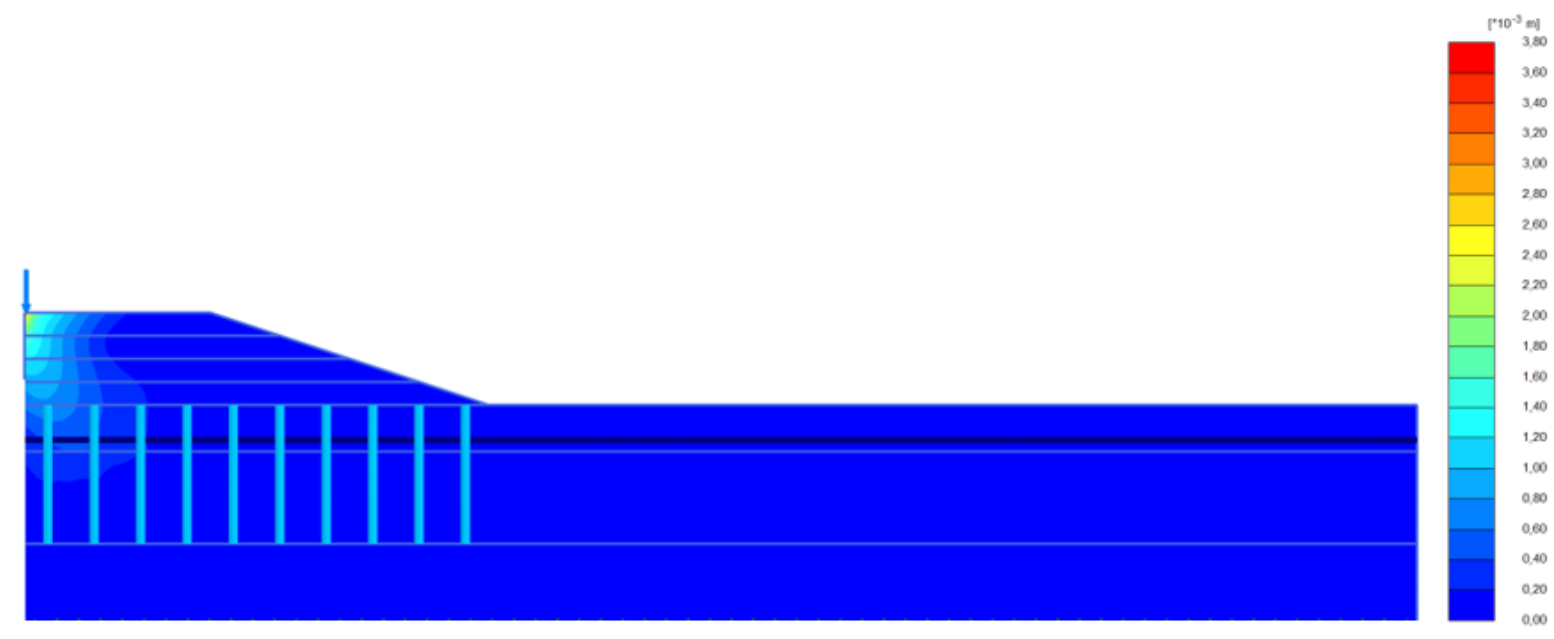

a

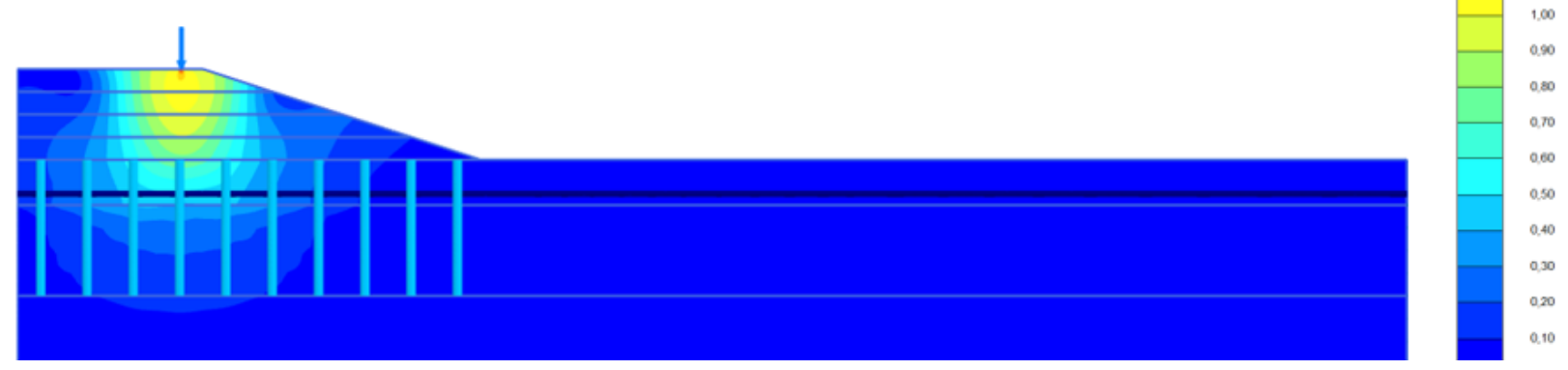

b

Şekil 9: Yükleme sonrası yol dolgusundaki toplam oturma davranışı; a) soldan yükleme, b) sağdan yükleme 


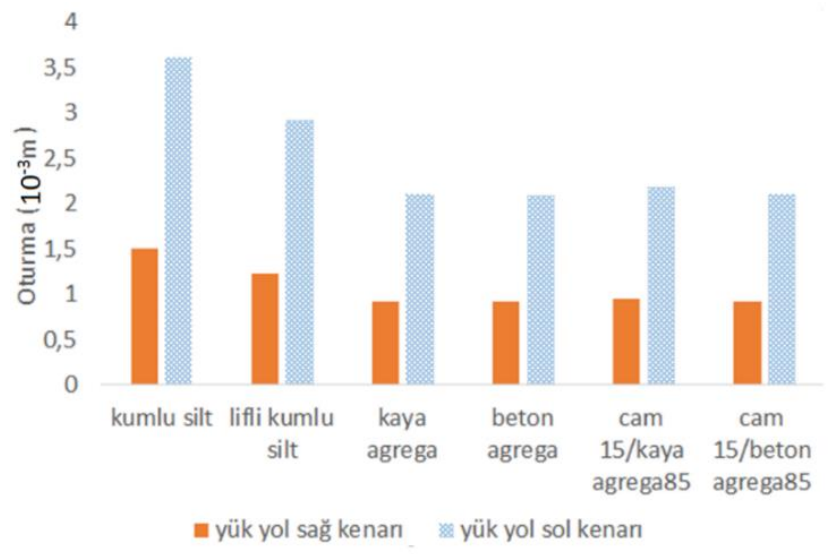

Şekil 10: Trafik yükünün yolun farklı bölümlerindeki oturmalara etkisine dolgu malzemelerinin etkisi

Geosentetik donatının trafik yükünden meydana gelebilecek toplam oturmaya etkisi Şekil 11'deki gibi hesaplanmış ve kumlu silt yol dolgusunun geosentetik donatısız durumunda elde edilen oturma sayısından geosentetik donatılı modelde elde edilen oturma sayısı arasındaki farklar hesaplanmıştır. Donatı sayısı 2 katına çıktıkça, oturma farkı sayısında yaklaşık 2 kat kadar artış görülmüştür. Diğer bir deyişle, geosentetik oturmayı azaltmakta ve donatı sayısı arttıkça da oturma miktarındaki azalma eğilimi daha fazladır. Yükün, şev merkezi veya kenarına yakın olması ise geosentetiğin etkisinde çok büyük değişimlere neden olmamıştır. Şekil 12'te ise dört adet geosentetikli örnekler lifli ve lifsiz dolgu malzemesi için incelenmiştir. Kumlu silt içine atık lif konulduğunda beklendiği üzere oturma miktarı lifsiz olan modele nazaran daha az olmasına rağmen geosentetiğin etkisi daha küçük olmuştur. Böylece de, lifli modeldeki yüklemede görülen oturma farkı daha az çıkmıştır. Yani, geosentetik daha zayıf yol modeli için daha aktif davranmıştır.

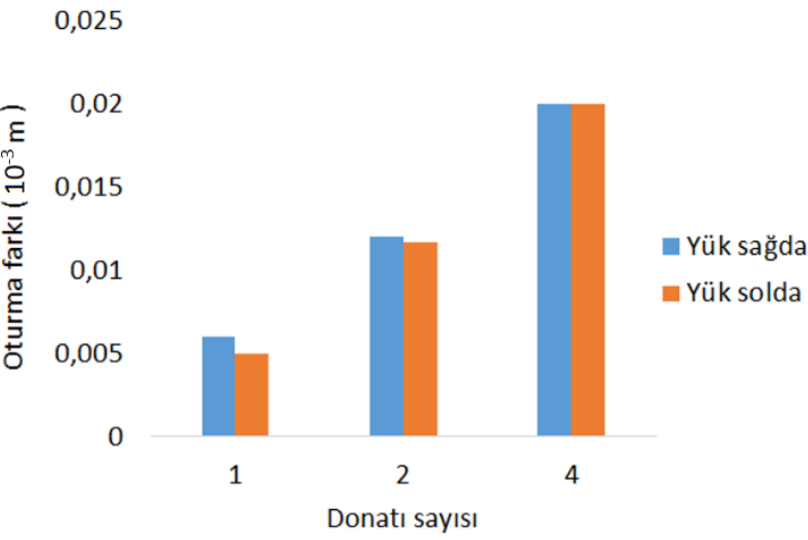

Şekil 11: Geosentetik donatı sayısının kumlu silt dolguda trafik yükünden oluşabilecek toplam oturmaya etkisi 0,025

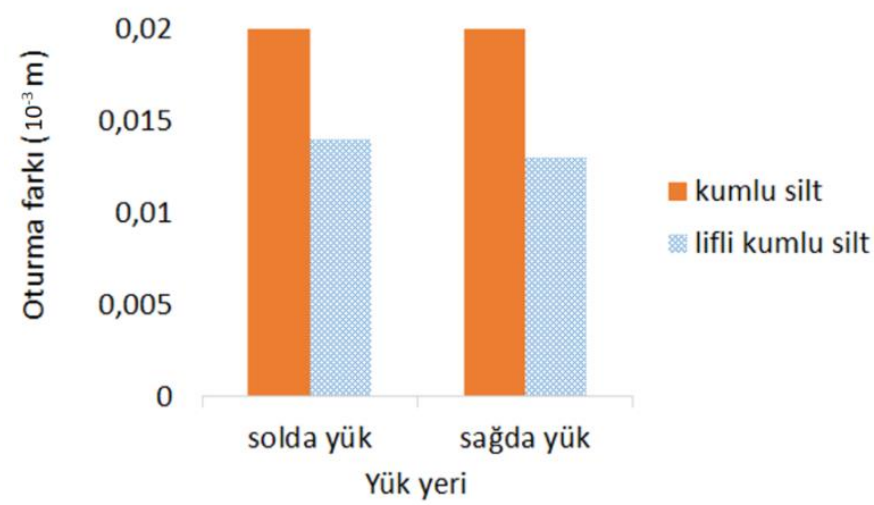

Şekil 12: Dört adet geosentetik donatının farklı dolgularda trafik yükünden oluşabilecek toplam oturmaya etkisi 


\section{Sonuç ve Öneriler}

Farklı malzeme çeşitleri için yol dolgu güvenliği için sonlu eleman analizleri yapılmıştır. Çevreci ve daha ekonomik çözümler için atık malzemelerin de yol dolgusu içinde kullanılması durumu incelenmiş ve konsolidasyon oturmaları ile ani göçmelere karşı güvenlik sayıları değerlendirilmiştir. Lif ve geosentetik donatının etkileri de belirlenmeye çalışılmıştır. Ayrıca, yolun farklı yönlerde yüklenmesi ile oluşabilecek trafik yükünden kaynaklı oturma sonuçları da yorumlanmıştır. Aşağıda elde edilen sonuçlar özetlenmiştir.

- Yol dolgusu seçilen malzemeler ile güvenli bir şekilde taşınabilmiştir.

- Farklı malzeme türlerinin yol dolgusuna etkisi incelendiğinde her malzeme türünün kendi içinde değişik davranabildiği görülmüş ve yapım sonrası ile konsolidasyon sonrası elde edilen güvenlik sayıları arasındaki farkın da değiştiği belirlenmiştir.

- Atık lif yol güvenliğini arttırmıştır.

- Beton atıklarının geri dönüşüm ile parçalanarak agrega gibi kullanılması durumunda, doğal duruma nazaran daha iyi bir yol dolgusu elde edilebilmiştir. Ayrıca, cam atıklarından üretilen agrega beton agrega ile karıştırıldığında kaya agregadan daha güvenli bir sonuç vermiştir.

- Yol altında kum malzemelerin olması yapım sonrası ile konsolidasyon sonrasındaki güvenlik sayıları arasındaki farkın az olmasını sağlamıştır. Kaya agreganın en fazla farkı verdiği ve kumlu siltli yol dolgusunun ise daha az fark oluşturduğu belirlenmiştir.

- Yol dolgusu içine geosentetik donatı konulduğunda tek donatıda dahi güvenlik sayısı 1.5 kat artmıştır. Farklı malzeme türlerinde geosentetiğin etkisinin de değişebildiği görülmüş ve atık lif konulduğunda geosentetik donatının etkisi lifsiz duruma nazaran daha az çıkmıştır. Ayrıca, yol dolgusunda kullanılan malzeme ne kadar zayıfsa geosentetik donatının etkisi de artmıştır.

- Konsolidasyon oturması tamamlandıktan sonraki yolun güvenlik sayıları arasındaki fark, dolgu içine geosentetik konuldukça değişmiştir.

- Yolda meydana gelebilecek tekerlek yükü etkisi de farklı malzemelerde değişiklik göstermiş ve en fazla oturma yol dolgusunun kumlu silt ile inşasında görülmüştür. Geosentetik donatı ise oturmayı azaltmış ve donatı sayısı arttıkça da oturma miktarındaki azalma eğilimi daha fazla olmuştur.

Sonuç olarak, geri dönüşümden elde edilebilecek malzemeler hem yol güvenliğini sağlayabilecek, hem atıkların değerlendirilmesi ile çevreci olabilecek hem de maliyet açısından yol yapım ekonomisine katkı sağlayabilecektir. Ayrıca, farklı malzemeler yol dolgusu için kullanıldığında değişik etkiler görülebileceği, sabit bir yaklaşım olamayabileceği ve dolgunun su drenajı ve güvenlik sayılarına etkilerinin de değişebileceği belirlenmiştir.

\section{Kaynaklar}

Ahirwara S.K., Mandala J.N., (2017), Finite element analysis of flexible pavement with geogrids, Procedia Engineering, 189, 411416.

Ali M.M.Y., (2012), Geotechnical characteristics of recycled glass in road pavement applications, Doktora Tezi, Swinburne University of Technology, Melbourne, Avustralya.

Arulrajah A., Piratheepan J., Disfani M.M., Bo M.W., (2013), Geotechnical and geoenvironmental properties of recycled construction and demolition materials in pavement subbase applications, Journal of Materials of Civil Engineering, 28, $1077-88$.

Brinkgreve R.B.J., Broere W., Waterman D., (2018), Plaxis 2D tutorial, Netherlands. https://www.researchgate.net/publication/ 262012153_Plaxis_2D_-_Version_8, [Erişim 15 Haziran 2019].

Çiçek E., Güler E., Yetimoğlu T., (2015), Sedde şevlerinin geosentetik ile donatılandırılmasının stabiliteye etkileri, EÜFBED - Fen Bilimleri Enstitüsü Dergisi, 8(1), 100-114.

Djellali A., Houam A., Saghafi B., Hamdane A., Benghazi Z., (2017), Static analysis of flexible pavements over expansive soils, International Journal of Civil Engineering, 15, 391-400.

Evangelista L., Brito J., (2007), Mechanical behaviour of concrete made with fine recycled concrete aggregates, Cement and Concrete Composites, 29 (5), 397-401.

Herrador R., Perez P., Garach L., Ordonez J., (2012), Use of recycled construction and demolition waste aggregate for road course surfacing, Journal of Transportation Engineering, 138(2), 182-190.

Jamsawang P., Yoobanpot N., Thanasisathit N., Voottipruex P., Jongpradist P., (2016), Three-dimensional numerical analysis of a DCM column-supported highway embankment, Computers and Geotechnics, 72, 42-56.

Liu H., Won M.S., (2009)., Long-Term Reinforcement Load of Geosynthetic-Reinforced Soil Retaining Walls, Journal of Geotechnical and Geoenvironmental Engineering, 135(7), 875-889.

Molenaar A.A.A., van Niekerk A.A., (2002), Effects of gradation, composition, and degree of compaction on the mechanical characteristics of recycled unbound materials, Journal of the Transportation Research Board, 1787(1), 73-82.

Oikonomou N.D., (2005), Recycled concrete aggregates, Cement and Concrete Composites, 27(2), 315-318.

Park T., Tan S.A., (2005), Enhanced performance of reinforced soil walls by the inclusion of short fiber, Geotextiles and Geomembranes, 23, 348-361.

Poon C.S., Chan D., (2006), Feasible use of recycled concrete aggregates and crushed clay brick as unbound road sub-base, Construction and Building Materials, 20(8), 578-585. 
Rahman M.A., Arulrajah A., Piratheepan J., Bo M.W., Imteaz M.A., (2013), Resilient modulus and permanent deformation responses of geogrid-reinforced construction and demolition materials, Journal of Materials of Civil Engineering, doi: 10.1061/(ASCE)MT.1943-5533.0000824.

Ramos-García J.A., Castro M., (2017), Linear visco-elastic behavior of asphalt pavements: 3D-FE response models, Construction and Building Materials, 136, 414-425.

Saevarsdottir T., Erlingsson S., (2015), Modelling of responses and rutting profile of a flexible pavement structure in a heavy vehicle simulator test, Road Materials and Pavement Design, 16(1), 1-18.

Yu Y., Jianhui Z., Xu Z., Xiaodong P., Hongwei L., Hao C., (2017), Finite element analysis of embankment with soft foundation reinforced by geogrids, Modern Civil and Structural Engineering, 1(1), 78-83.

Zhang J., Zhu C., Li X., Pei J., Chen J., (2017), Characterizing the three-stage rutting behavior of asphalt pavement with semi-rigid base by using UMAT in ABAQUS, Construction and Building Materials, 140, 496-507. 